\title{
Circling the Cyclone: Children's Understanding of Natural Disasters through the Arts
}

\author{
Ute Haring, ${ }^{1}$ James Cook University, Australia \\ Reesa Sorin, James Cook University, Australia \\ Nerina Caltabiano, James Cook University, Australia
}

\begin{abstract}
Natural disasters can occur unexpectedly with devastating effects as attested by recorded history documents. They have caused immense suffering and destruction. In recent years, natural disasters have increased due to climate change. Further, the need for public awareness of catastrophic events has also increased, along with the media push to prepare for these events. Disaster preparedness has reduced loss of life and property, and children have demonstrated that they have the capacity to be actively involved in disseminating important and useful disaster information and the ability to assist with disaster preparedness in their families. Therefore, disaster preparedness is now an established part of the school curricula. However, while the topic of natural disasters is increasingly being included in school curricula, teachers may still feel uneasy introducing students to this topic. If they have not experienced a natural disaster and are not aware of the severity of disasters, teachers may lack the necessary information to best educate and support children. Further, teachers may need to tread a fine line between transmitting facts and shocking students with the emotive results of disasters. This is further exacerbated by media reporting. Arising from a document study of children's drawings from the 2006 Cyclone Larry natural disaster in tropical north Queensland, Australia, and research into cyclones, this paper presents strategies, including a poem, for teachers to introduce natural disasters to students in the upper primary school years. It may help to facilitate understanding about natural disasters and preparedness for these occurrences.
\end{abstract}

Keywords: Natural Disasters, Cyclone Preparedness, Children, Aboriginal Rainbow Serpent Myths, Cyclone Poetry, Qualitative Research

\section{Introduction}

"The cyclone ends. The sun returns;
the lofty coconut trees lift up their plumes again; man does likewise.
The great anguish is over; joy has returned; the sea smiles like a child."

(Gauguin, n.d.)

$\mathrm{T}$

This research is based on the question, "How can the arts be used to teach children about natural disasters, particularly cyclones?" The article begins with a discussion about how to introduce sensitive disaster information to students. Although natural disasters in the tropical North Queensland area of Australia include droughts, floods, bushfires, and cyclones, this paper will focus on the natural disaster of cyclones. The discussion is followed by a poem, developed out of the first author's research, introducing the topic of cyclones while conferring facts about the three stages of a cyclone and the disastrous effects it can have on people and the environment. This theme is juxtaposed with musical terms and an Aboriginal myth about the Rainbow Serpent. Teacher notes about how to use the poem to facilitate learning about cyclones support the poem. The researchers have found that art such as poetry, along with visual and performance arts, provide innovative, age-appropriate, and child-centred ways to effectively teach children about natural disasters.

\footnotetext{
${ }^{1}$ Corresponding Author: Ute Haring, PO Box 6811, College of Arts, Society and Education, Division of Tropical Environments and Societies, Cairns, Queensland, 4870, Australia. email: ute.haring@my.jcu.edu.au
}

The International Journal of Pedagogy and Curriculum

Volume 25, Issue 4, 2018, http://thelearner.com

(C) Common Ground Research Networks, Ute Haring, Reesa Sorin, Nerina Caltabiano,

Some Rights Reserved, (CC BY-NC-ND 4.0). Permissions: support@cgnetworks.org

ISSN: 2327-7963 (Print) ISSN: 2327-9133 (Online)

http://doi.org/10.18848/2327-7963/CGP/v25i04/1-15 (Article) 


\section{Natural Disasters Discussed}

According to the "World Disaster Report 2001" (quoted in Keeney 2004, 2), "Every year, disasters affect tens of millions of people, cause economic losses of tens of billions of dollars, and kill tens of thousands of people." In recent years, natural disasters such as earthquakes, droughts, bushfires, floods and cyclones appear to have increased due to climate change (Boon 2014). Van Aalst $(2006,5)$ postulates that climate change is mainly due to "anthropogenic greenhouse gas emissions," which might trigger further extreme weather. We can assume that future generations will be severely affected by further increasing disasters (Boon 2014; Kousky 2016).

Natural disasters can happen unexpectedly; vary in frequency and intensity; and cause enormous destruction, loss of life and property (Fuhrman et al. 2008). They are "frightening events and difficult for us to understand because they strike indiscriminately and we have no control over them" (Woods et al. 2014, 10). Children, in particular, find it difficult to accept natural disasters as "chance happenings." Due to their young age, children may perceive a natural disaster as a punishment for something they did (Shaw 2012, 18), as the "magical thinking of young children can lead to misinterpretation of events" (Coffman 1998, 376).

Keeney $(2004,1)$ defines disasters as "events that exceed the capacity of the people affected to recover from the adverse effects." Research has shown that children are amongst the most vulnerable during and after a disaster due to their developmental life stage (Boon and Pagliano 2014). Elangovan and Kasi (2014), as well as Grindlay and Breeze (2016), state that the impact on children who experience a disaster will be much stronger than on adults and might lead to psychological, emotional, and social difficulties that last well into adulthood. Kousky (2016) warns that in the next ten years, 175 million children will be involved in a natural disaster. As disasters, both natural (e.g. cyclones, flooding, earthquakes) and human-made (e.g. oil-spills, terrorist attacks, nuclear explosions/radiation) have increased in recent time; children will not only experience disasters, but are also exposed to these events daily in the media, increasing their fear of living in an unpredictable and unstable world (Boon and Pagliano 2015; Fuhrmann et al. 2008; Haring, Sorin, and Caltabiano 2017; Wooding and Raphael 2004). According to Sorin (2003), fear of the unknown is the strongest emotion a child might ever feel. If this is exacerbated by visual content, depicting disasters without much context provided, children may develop feelings of extreme fear, helplessness, and empathy for the suffering of innocent people, which in turn may lead to lasting trauma particularly in sensitive children (Haring, Sorin, and Caltabiano 2017).

Research has shown that disaster preparedness can be most effective if discussed openly and if delivered appropriately in schools and communities (Boon and Pagliano 2015). According to Fuhrmann et al. $(2008,113)$, it is important to "educate [about disasters], but not to scare children" about disasters. However, how a child responds to disaster depends on a "complex interplay of pre-existing vulnerability, differing stressors and differing impact" (Wooding and Raphael 2004, 10). Overall, researchers have found that teachers need to carefully select, view and screen the material they want to deliver in their classes; bearing in mind the age and developmental stage of the students. Further, they must have a professional and intuitive knowledge of the psychological make up of individual students (Boon and Pagliano 2015; Haring, Sorin, and Caltabiano 2017). As Boon (2014), Dufty (2014), and Sorin (2003) found, knowledge and realistic fear gives children a feeling of power over an unpredictable situation, increasing resilience, thus aiding in situations of disaster preparedness and disaster recovery.

Resilience is a term that is increasingly being used in the disaster literature. Indeed, "resilience" was the focus of the World Disaster Report 2016 (WDR 2016, 12-13). The term has been defined as a word that might have varied meanings in different languages or cultures. Universally it can be assumed that resilience means an individual's or a community's ability to "bounce back" after a disastrous experience. However, the WDR authors ask: "Bounce back to 
what?" (WDR 2016, 14). It certainly would not mean going back to the same situation people found themselves in before their predicament, particularly in disaster situations. Therefore, building resilience would mean to update essential factual knowledge and train people to react appropriately when disaster strikes, thereby nurturing disaster preparedness (Izadkhah and Hosseini 2005, 139).

Following the natural disaster of Hurricane Katrina, a teacher-based intervention developed in Israel, was implemented (Baum et al. 2009, 63). Termed "The Building Resilience Project" (BRP), workshops trained teachers to cope with their own trauma reactions to be able to help children who had been exposed to disaster. The authors state that "emotional processing, returning to routine and distraction" serves to develop resilience in children.

Boon et al. (2012, 385-86) found that "resilience includes factors such as the will to live, perception of a situation as challenging, a sense of commitment and control, a sense of meaning, self-efficacy and learned resourcefulness." The authors see resilience as a "dynamic process that develops in individuals over a period of time." To encourage resilience in children there is a need to not only educate them in disaster preparedness, but also for important adult "allies" such as teachers and parents to provide them with the assurance that they "can still go on, grow, and strive for a future of hope despite their fears" (Berson and Baggerly 2009, 378).

The World Disaster Report (WDR 2016) concludes that due to improved preparedness, many community disaster effects have been reduced. As scientists predict further extreme events due to climate change and an increase in population growth globally, the WDR (2016) demands that internationally, pre-disaster education is absolutely necessary. Boon and Pagliano (2014) report that school disaster education is also necessary, as knowledge about possible disastrous events in certain areas of the world can help the population to actively introduce protective measures.

Disaster education has been found to be most effective if delivered in schools and disseminated by students into family and community. Mangione et al. (2013, 130-32) suggest using "innovative pedagogies" to distribute information about disaster preparedness, labelling this information "risk education" or "safety education." They demand that a program should motivate, "creatively engage learners," build problem-solving abilities, and establish "personal responsibility" for disaster preparedness.

Ronan et al. $(2015,7)$ note that disaster education hardly exists internationally, even though research and literature has supported its implications in recent years. They evaluate Disaster Risk Reduction (DRR) courses, questioning whether universal DRR programs actually achieved their purpose: to "decrease risks and increase resilience." Lane and Catling (2016) and Ronan et al. (2016) ask for pre-service teacher training in geography-related disaster preparedness, which is still missing in their university courses.

\section{The Cyclone in Australian Subtropics}

Australia's climate ranges from subtropical in the North to temperate in the South. While the coastal areas are densely populated, the inner regions, with their desert features, are sparser. Overall, weather patterns in all parts of Australia can be extreme: droughts, bushfires, cyclones and floods can be expected yearly (Boon and Pagliano 2014), putting immense pressure on the population, emergency management, state finances, and insurance companies.

In tropical north Queensland, cyclones develop regularly in the cyclone season, which lasts from November to April. Cyclones are huge, spinning storms and pose a serious threat to the Queensland coastal areas, the community, individuals, commercial infrastructures, the land, animals, and plants (Haring and Sorin 2016). A cyclone's development could be influenced by an El Nino (a drier year for Australia) or a La Nina year (more rainfall can be expected). This shift in weather patterns happens every three to eight years and depends on warming streams over the Pacific Ocean (ABM 2016). Generally, a cyclone needs a low-pressure system to form over tropical waters, which have a $26.5^{\circ} \mathrm{C}$ temperature. 
Ocean water evaporates and clouds form and begin to rotate. Cyclones in the southern hemisphere rotate clockwise and can follow erratic paths, gathering more mass and speed. Tropical cyclones are categorised by their strong wind gusts. A severe tropical cyclone is announced if the wind gusts surpass $165 \mathrm{~km}$ per hour (category 3), but winds can exceed 280 $\mathrm{km} / \mathrm{h}$ (category 5).

There are three parts to a cyclone: the first stage is "the lead up," in which a cyclone is declared and state warnings are given. Further, the community is advised to hurry last-minute preparations (Haring and Sorin 2016). The second stage is "the landfall," when the cyclone reaches land with destructive wind gusts, massive rainfall, floods, and storm surges. In the middle of the storm comes a relatively calm period when the "eye" of the cyclone passes over. Then the cyclone continues, with winds in the opposite direction causing immense destruction in its path. Cyclones usually dissipate over land, but can still affect huge inland areas (ABM 2016). The third stage is "the aftermath" of a cyclone, where loss of life and property is counted and a fresh start to life begins (Haring and Sorin 2016).

Two of the authors previously published an account of cyclone activity, including how children reacted to the experience of living through the 2006 Cyclone Larry (Haring and Sorin 2016). Findings confirmed that children supply important contributions to our understandings of cyclone awareness and preparedness.

\section{Efforts in Australia to Increase Disaster Awareness and Preparedness among Children in Schools}

In Australia, Emergency Management Authorities taught disaster programs in schools around the country in areas where natural events have occurred. Following this, the Australian National Curriculum (n.d.) finally introduced disaster and geography education for every state. This subject is taught in Years 6, 7, and 8 and again in Senior Secondary Geography (Boon and Pagliano 2014). Dufty (2014) advises to include natural hazard activities in different subjects, ensuring that students have more than one lesson and that revision is included each year to limit forgetfulness. It has been found that generally, people are inclined to become complacent after a disastrous event and might be complacent in preparing adequately for another (Usher et al. 2013), especially when the event failed to meet the predicted expectations.

Fuhrman et al. $(2008,119)$ recommend including information about disaster preparedness "in almost any class situation, ranging from geography, history, economics, civics, social studies, language, arts, mathematics, science, physical education, health, and technology." Lessons in geography and science should include facts about climate change and global warming as well as disaster preparedness. Students will be challenged to discuss their own, often "naïve" theories based on popular TV shows or films (Lane and Catling 2016), such as how cyclones develop and their influence on land and people (Lane and Coutts 2012).

Teaching material can be found online in the Australian Curriculum Assessment and Reporting Authority (ACARA) site, including links to planning tools and units of work. This is supported by the State of Queensland Studies of Society and Environment (SOSE) sourcebook modules (2000). Further, Berry and King (1998) developed a program called "Stormwatchers," a cyclone-awareness education package for upper primary school children. Using five scenarios, students are challenged to prepare for a cyclone. More recently, the American Red Cross' (2016) "Pillowcase Project: Learn, Practice, Share" covers natural disasters in an engaging way that can be used in Upper Primary and Middle School. Further studies need to assess how actively this teaching material has been implemented in schools and to what effect.

Fuhrman et al. $(2008,113)$ discuss teaching material for disaster preparedness in geography lessons. They offer various information and web links, based on the US National Geographic standards, on how to implement disaster preparedness in academic subjects. Their review and research into the literature about disaster events produced "seven lesson-plans for elementary, 
middle and high school levels." Equally, Ronan et al. (2016) call for further research internationally to be conducted into the effectiveness of disaster preparedness programs.

According to Boon and Pagliano (2015), a literature review of articles published about disaster programs in Australia showed the necessity for a "thorough examination and evaluation of school-based disaster education curricula" that would actively involve children (193). But, as Dufty (2009) reported, disaster management authorities usually assume that children will take knowledge from disaster preparedness programs at school to their families and the community. This, however, does not necessarily mean that parents were factually informed or that extensive preparations for disasters were actually implemented, though Boon and Pagliano (2014) observed that, if children are actively involved as agents in disaster preparedness, their families and the communities benefit. The natural curiosity and enthusiasm of children can provide the basis for effective learning (Ronan et al. 2008), especially if a pedagogy is employed that "brings knowledge to life, practices skills, challenges attitudes, scrutinises values, [and] is a pedagogy that is active, interactive, experiential and participatory" (Selby and Kagawa 2012, quoted in Mangione et al. 2013, 132).

Despite emerging efforts to include disaster preparedness in school curriculum, there is little research that discusses specific and concrete ways that such content and material can be implemented in schools in child-centred and child-friendly ways. This current research extends the theme of teaching disaster preparedness using arts-based teaching such as drama and poetry.

\section{The Importance of Arts-Based Teaching of Drama and Poetry}

Arts-based teaching methods have the potential to offer innovative and child-friendly ways to inform children about natural disasters and emergency preparedness. Malchiodi $(2009,2)$, an art therapist, strongly endorses the use of the arts in teaching. Citing Perry's research into "neurosequential therapeutics," she argues that in storytelling, poetry and drama, a child's imagination gets fired, instructing the brain to develop "new neuro pathways." This helps to improve resilience and will aid a child when placed in a survival situation.

Malchiodi $(2009,1)$ maintains that "art, play and imagination" are sensory interpolations necessary for the developing brains of children. Similarly, Alat $(2002,2)$ postulates that in connection with trauma, teachers would try different approaches if they knew the positive effects the arts have on the "cognitive, behavioural and physio-somatic" development of children. Lusebrink (2004) and Frost (2005) affirm that sensitive, arts-based experiences improve children's mental health. Arts-based methods allow teachers to try new ways to dynamically engage students in discussing different issues, particularly sensitive ones. According to AshtonHay $(2005,1)$, drama in particular "is highly regarded as an effective and valuable teaching strategy because of its unique ability to engage reflective, constructivist and active learning in the classroom."

In middle and upper primary school, involvement in arts-based activities such as drama and poetry provides students with tools to make sense of the world around them and to empathise with other people (Gangi and Barowsky 2009). In fact, according to Frost (2005), the mental health of students is improved when teachers employ art activities to help students cope with trauma. Further, arts-based activities help facilitate learning in other important core curriculum courses such as English (Gattenhof 2014, 2). In drama, students explore "voice, movement, situation, space and time." According to Ferguson (2014), drama enlivens poetry, helping to understand content and meaning. Additionally, Flensburg $(2010,16)$ sees poets as "eloquent tour guides on the journey to sharpen our awareness of nature." Smilan (2009, quoted in Guss 2005, 381) encourages the "poetic illusion" of drama as it supplies direct human interaction

As Hopkins states, "poetry...opens up a world of feeling for children they never thought possible; it is a source of love and hope that children carry with them the rest of their lives" (quoted in Danielson and Dauer 1990, 138). Smilan (2009, quoted in Guss 2005, 48) affirms that using drama in teaching is a necessity for children in general, as it builds a connection between 
"Erlebnis" and "Erfahrung" (meaning that the experience produces excitement as it is lived through and, when later reflected on, turns into experience).

Findings from previous research suggest that art gives children a voice to express feelings (Haring 2012), as fears of danger and death resurface after disasters (Haring and Sorin 2016). Art-making as a tool for healing also encourages children's resilience by engaging them as mediators and not as victims. The art forms described in this paper are poetry and drama, which can be used not only for increasing understanding of natural disasters, but also as a tool for building resilience.

\section{Experiencing a Cyclone in Drama and Poetry}

The following poem concerns the development of cyclones off the Far North Queensland coast, Australia, and the influence on children who lived through the cyclone experience (Haring and Sorin 2016). The poem could be introduced to an upper primary classroom during social studies, cyclone research, English, or drama lessons. In the poem, three different themes are explored, described, and juxtaposed - the Aboriginal myth of the Rainbow Serpent creator, the different stages of a cyclone, and musical terms and definitions - thus achieving a multilayered effect (Guss 2005). Each theme is elaborated below.

According to Tacon (2005), many places within the Australian landscape give rise to the creation of myths. These locations are particularly significant, unusual, and important parts of the environment. They are said to be established by Ancestral Beings and spirits, who still care for them.

The most important myth is that of the Rainbow Serpent, known by different names throughout Australia (Tacon 2005). The mythological serpent lived near water, in billabongs or waterfalls, and created the world in the "Dreamtime" (Australia Lesson Activities-Literacy 2001). Dreamtime "refers to Aboriginal mythologies of creation and the earliest period of human life, when interaction with powerful entities shaped landscape, the biomass and human destiny" (Hayward 2010, 22). During this time, valleys developed from the winding motion of the serpent's body, while mountains were pushed up by its muscles and tail. Its colours later appeared in the rainbow (Burge 2015).

Although a creative and benevolent creature, the rainbow serpent was also known to produce great disasters, such as cyclones and floods, if following generations did not care for the land and keep oral mythology alive. According to the Art Gallery of NSW $(2015,1)$, "the destruction of Darwin by cyclone Tracy, [is] understood to be the retributive act of the Rainbow Serpent, warning against the decline of Indigenous cultural practices." Aboriginal spirituality is deeply entwined with everyday life and "mystical realities" and gives individuals a sense of belonging and identity (Skrzypaszek 2011, 132).

The rainbow serpent is a focus of the poem discussed here. The poem itself follows the three stages of a cyclone - the developing storm, the storm making landfall, and the aftermath - and aligns each stage with a musical term (Carney 2015). The terms have been arranged in order of the intensifying and then diminishing cyclonic storm. The poem is based on children's experience and description of Cyclone Larry in 2006 (Mothers Helping Others 2006): how the wind and rain changed the atmosphere, how rain-gusts and crashing trees produced an incredible noise, how the light changed from golden in colour to a misty grey, and how the rain-soaked earth had a musty fragrance until fresh rain fell after the storm passed (Haring and Sorin 2016).

The musical terms might be already familiar to some children, as ten-to-twelve-year-old students often receive piano lessons. This poem follows a simple A, B, B, A, C structure and is written in mixed meter, modelled from the intensity and wind-strength of a cyclone (mixed meter: rhythm shifts between a metrical pattern [Moustaki 2001]). The poem and teacher notes follow, and ideas for teaching about cyclones and other disasters are included. 


\section{Tale of a Cyclone}

After the rains had stopped

For many months

The earth was as dry

As a mud-cake in the sun.

"Pianissimo," the teacher said,

"Play softly like the cool breeze

Twirling dry leaves of the gum trees

Behind the old farm shed

Near the billabong."

"Staccato! Now let your fingers hop

Like the Kookaburra sang to the sun

On the very first morning the world had begun

By rainbow snake's creation of valley and mountain top

In the dreamtime."

“Animato! That's lively now and bright-

Remember the stories of old, around campfires told

Of the rainbow snake's thundering bold,

Dripping colour from scales in brilliant light

Through the sky."

"Fortissimo! The rainbow snake roared

Woken from sleep, millennia deep by echoes of human construction

Trees screaming, wildlife beaming- gone in destruction

Trucks and chainsaws deplored-

Under the Southern Cross."

"Feroce! The serpent's anger fiercely sparking fire,

Bellowing steam into swirling cloud

Gushing water fills creeks and rivers loud,

Toying with dreamtime desire

For peaceful beauty."

"Crescendo! Remember the roof flying,

Trees creaking, crashing, windows smashing

Cyclonic wind....lashing

Hear the serpent's annoyed sighing

About mortals' folly.

"Grandioso! Play in a great style:

Eye of the storm looking down on shifting shade

Stillness sits waiting, afraid-

Watching the swirling air a while

In immense solitude."

"Furioso! Violent path of cyclone returning

Due to rainbow snake's wild scorn 
Trees de-leaved like flagpoles torn;

Houses bashed, in rising waters churning

Following the Inland-Sea."

"Andante! Actually walking quietly around

Families unite with friends

Troubled minds find healing hands.

Hope leaps homeward-bound.

Tapestry of life restitched."

"Dolce! Play sweetly like butterflies rejoice-

Rainbow whispers colours, pleased-

Serpent for another year appeased

Dance and clap-sticks lift their voice -

Ancestral devotion renewed."

\section{Deconstructing the Poem}

In the poem, musical terms and definitions are explained by an imagined piano teacher. The terms have been arranged in the order of the cyclonic progression. Introductory lines preface the warm weather and resulting drought in North Queensland, Australia. Each verse is summarised below.

- Verse 1: Paints the landscape and the dry condition of the land. "A billabong ("bill-abong') is a body of water, like a large pond" (Billabong, n.d.).

- Verse 2: Introduces the world created by the Rainbow Serpent, as told in Indigenous mythology (Australia Lesson Activities 2001). "The 'Laughing Kookaburra' is an Australian bird singing/laughing in the dawn chorus" (Kookabura, n.d.).

- Verse 3: Explains how the serpent painted a colourful world (Burge 2015).

- Verse 4: Tells of the serpent's awakening as prophesised (Burge 2015, 1). The Southern Cross is a collection of five stars "in the night sky [which] has guided travellers, intrigued astronomers and inspired poets and musicians." (Maher 2014).

- Verse 5: The serpent produces a cyclone and floods (Tacon 2005).

- Verse 6: Describes the effects of the cyclone on trees, houses, and people (Mothers Helping Others 2006).

- Verse 7: The eye, or middle of the revolving cyclone, quietly passes over the land. (ABM 2016).

- Verse 8: The cyclone returns with winds and floods, carrying houses and possessions (Mannix 2012) toward the mythological Inland Sea (Great Australian Inland Sea 2018).

- Verse 9: People in the community help each other to cope. Life begins to return to "normal" again (Mothers Helping Others 2006).

- Verse 10: The Rainbow Serpent has been calmed. Animals reappear. The serpent goes back to sleep in the billabong. Devotion to the Rainbow Serpent has been re-established: after destruction comes renewal of myths and traditions. 


\section{Experiencing the Poem}

The poem can be read or spoken as a chant by a group of students or single voices intonating the cyclone. A chant is a "form of oral poetry...to be communally performed...something between a speech and a song" (Moustaki 2001, 316). Or, as Forster $(2006,64)$ writes, "chants are stretches of real language put into a rhythmic framework."

\section{Learning about the Australian Landscape and the Dreamtime}

Teachers and students will find many ways to perform and/or use this poem. Students could be challenged to set the poem to music, explain the different musical terms, and accompany this with movement and expression (Flensburg 2010). Danielson and Dauer $(1990,140)$ suggest that "creative movement to music or poetry adds to the mood and meaning of a poem." Further, costumes and background stage sets could be created by students. The following section lists ideas for teaching and learning that could be used in upper primary classes to facilitate student learning about cyclones, the Dreamtime, and musical annotation.

The poem could be linked to the poem "My Country" by Dorothea Mackeller (1908). This poem describes the Australian landscape, and is the origin of the saying, "I love a sunburnt country." It mentions droughts and flooding rains, leading easily to the topic of cyclones. Students could read it, deconstruct it, and look for parallels between this poem and "Tale of a Cyclone." Teachers' notes to "My Country" are available online at http://www.iread.com.au/schools/education/teacherresources/assets/pdfs/My\%20Country.pdf

\section{Possible Questions to Ask:}

a) What does the author tell us about Australia when she compares it to her motherland, England?

b) What does the English landscape in the first verse sound like, feel like, smell like?

c) What does the author say about the landscape and the extreme weather in Australia?

d) What is different in Australia, and why does she love the difference?

e) List words chosen by the poet to describe why Australia is beautiful, but also terrifying.

f) What is the "blessing" to the people and the land?

g) Why would the poet be homesick for Australia when England's weather would be gentler and more welcoming to her?

h) Compare "My Country" to "Tale of a Cyclone." Is there a similar love of the country, despite the extreme weather condition and the threatening cyclone? How is it shown?

i) Why would Indigenous people tell the story of the Rainbow Serpent over thousands of years? Where is the connection to the serpent in the poem by Mackeller?

j) Draw two pictures, contrasting the two different countries the poets talk about.

Another well-known poem that describes the often extreme weather conditions in Australia was written by Father Hartigan (alias O'Brien) in 1921, in response to observing his parishioners. It is titled, "We'll All Be Rooned,' said Hanrahan." The poem demonstrates how people feel at the mercy of the weather, as their livelihoods depend on it. More information is available at http://www.catholica.com.au/brianstake/010_bt_print.php. 


\section{Possible Questions to Ask:}

a) Where in Australia could this poem be situated? Why?

b) Who is the main character in the poem, and what is his attitude to the situation?

c) What effect does his attitude have on others?

d) Which sentence tells us about the seriousness of what is happening?

e) How many extreme weather conditions are described here? What are they?

f) Which repeated line tells us about the people having to accept what happens?

g) How do the farmers respond to each extreme season?

h) What descriptive language does the poet use for each weather condition?

i) What do you think happens after the poem ends?

j) Compare this poem to the "Tale of a Cyclone." Include which observations, descriptions, direct speech, sounds, feelings, smells, etc. are similar. Read together Mueller's story (January 12, 2011), "We'll Wade on as We Always Do," reported in The Telegraph: http://www.telegraph.co.uk/news/worldnews/australiaandthepacific /australia/8256085/Australia-Floods-Well-wade-on-as-we-always-do.html

Further, the poem, Rainbow Serpent was composed by Anthony Burge (2015). While walking through a dry, rocky riverbed in the Kimberly, he remembered Dreamtime stories. More information is available at https://www.poemhunter.com/best-poems/anthony-burge/rainbowserpent/.

\section{Possible Questions to Ask:}

a) How do the Indigenous people know about the serpent?

b) Where can the mythical rainbow serpent be found?

c) Which parts of the serpent can still be seen?

d) What will happen if the serpent awakes?

e) Besides brilliant colours, the serpent achieves several other things. How many can you find?

f) What happens to people not keeping the law?

g) How might animals be rewarded?

h) What is a "totem," and what is expected of those who have this totem?

i) Why does the poet call the serpent "Mother of Life"?

j) What might have motivated the poet to write this poem?

k) Look for parallels and find differences and agreements in this poem and "Tale of a Cyclone."

1) Draw a storyboard or comic-strip with speech-bubbles of what the serpent says and what the people think.

\section{Information}

About storyboards (n.d.):

https:/www.scholastic.com/teachers/articles/teaching-content/what-are-storyboards/

About the Dreamtime (n.d.)

https://www.aboriginal-art-australia.com/aboriginal-art-library/

Australian Indigenous Cultural Heritage (n.d.)

https://www.australia.gov.au/information-and-services/culture-and-arts/indigenous-

culture-and-history 
In "Tale of the Cyclone" (presented above in the text), the imagined piano-teacher uses the child's memory of the experienced cyclone and the Rainbow Serpent myth as a teaching tool. By evoking the imagination to remember the sound of the wind, the drops hitting the dry soil, and the changing lights and smells, the child can connect the musical terms with memory pictures.

\section{Possible Questions to Ask}

a) Make a list of the different musical terms and research the way they should be played.

b) What leads up to a cyclone? What is a cyclone? What is the "eye" of the cyclone?

c) What happens before a cyclone, during a cyclone, after a cyclone?

d) What can we find out about the "Inland Sea?"

e) What role does the Rainbow Serpent play in Aboriginal myths?

f) What happens if the serpent wakes up?

g) Why would the serpent be concerned about the current state of the environment?

h) List the words that mean "destruction."

i) List words that help to describe the situation.

j) Who are the main characters of this poem?

\section{Suggestions for Class Activities}

1) Draw a story-board imagining each verse, or create a collage.

2) Group work: write a summary of each verse in one sentence, report, discuss.

3) Present the poem as a vocal drama, remember "expressive features, such as emphasis, loudness, slowness" and "gestures and facial expressions" (Dinham 2011, 193).

4) Develop a drama performance with a group chorus and individual actors taking the parts of the narrator, the piano-teacher, the Rainbow Serpent, and the cyclone. The narrator introduces the first verse; then the piano teacher explains the first line while a group chorus tells what happens next.

5) Masks and/or costumes for the different characters could be designed, as well as different music for each verse, considering musical elements "such as dynamics, pitch, tempo, duration and tone colour" to bring the poem to life (Russell-Bowie 2006, 229). Further, sound effects of wind, rain, machine noise, etc. could be created by students and included. Diverse colours in props and scenery could contribute a dynamic visual impact to set the mood and context of the Australian landscape.

6) The poem also lends itself to the creation of a puppet play or even a dance/movement presentation.

\section{Conclusion}

Increasingly, natural disasters due to climate change demand extra alertness and preparedness globally. As worldwide population growth is also increasing - often in disaster-prone areasurgent provisions must be made to transmit knowledge about disasters and safety education. Research has documented that children can be agents for the dissemination of active, protective measures before disastrous events strike. Children display a natural curiosity and motivation to learn; therefore, schools are the places where children might be accurately informed about disasters, climate change, and global warming. This knowledge could be integrated into different subjects and brought to families and the wider community, depending on proper instructions or programs which consider the age and physical and emotional development of students in a childfriendly, age-appropriate way. 
As disaster education is now a part of the Australian Curriculum, preservice teacher education should include this topic to enable teachers to deliver correct information. Future research projects could examine the suggested activity and assess its effectiveness. Further, new programs could be developed to find creative ways to engage students in disaster education. The cyclone poem presented here could actively impact on both disaster knowledge and preparedness.

\section{REFERENCES}

Alat, K. 2002. "Traumatic Events and Children: How Early Childhood Educators Can Help." Childhood Education 79 (2): 2-7.

American Red Cross. 2016. The Pillowcase Project. Learn, Practice, Share. Washington, DC: American Red Cross. http://ymiclassroom.com/wp-content/uploads/2013/09/pp presentersguide.pdf.

Art Gallery of NSW. 2015. "Biography and Artist Profile of Rover Thomas." Art Gallery NSW. https://www.artgallery.nsw.gov.au/collection/artists/thomas-rover.

Ashton-Hay, S. 2005. "Drama: Engaging all Learning Styles." In Proceedings of 9th INGED (Turkish English Education Association) International Conference 'New Horizons in EL, 1-19. Ankara: Economics and Technical University. https://eprints.qut.edu.au/12261/1/12261a.pdf.

Australia Lesson Activities-Literacy. 2001. "Dreamtime Stories-The Rainbow Serpent." Australia Lesson Activities-Literacy. Accessed September 26, 2016. http://www.expedition360.com/australia_lessons_literacy/2001/09/dreamtime_stories the rainbow.html.

Australian Government Bureau of Meteorology (ABM). n.d. "About Tropical Cyclones." Accessed October 12, 2015. http://www.bom.gov.au/cyclone/about/.

2016. "El Nino Southern Oscillation." Accessed October 16, 2016. http://www.bom.gov.au/watl/about-weather-and-climate/australian-climate -influences.shtml?bookmark=enso.

Australian Indigenous Cultural Heritage. n.d. "Indigenous Culture and History." Accessed July 30, 2018. https://www.australia.gov.au/information-and-services/culture-and -arts/indigenous-culture-and-history.

Australian National Curriculum. 2016. "Science." Accessed September 15, 2016. http://www.scootle.edu.au/ec/search?accContentId=ACSSU096.

Baum, N. L., B. Rotter, E. Reidler, and D. Brom. 2009. "Building Resilience in Schools in the Wake of Hurricane Katrina." Journal of Child and Adolescent Trauma 2 (1): 62-70. http://doi.org/10.1080/19361520802694323.

Berry, L., and D. King. 1998. "Tropical Cyclone Awareness and Education Issues for North Queensland School Students. Stormwatchers-A Cyclone Awareness Education Package for Upper Primary School Children." Australian Journal of Emergency Management (Spring 1998): 25-30. https://ajem.infoservices.com.au/downloads/AJEM $-13-03-08$.

Berson, I. R., and J. Baggerly. 2009. "Building Resilience to Trauma. Creating a Safe and Supporting Early Childhood Classroom." Childhood Education 85 (6): 375-79. https://doi.org/10.1080/00094056.2009.10521404.

Billabong. n.d. "Rivers Continuing in Time." Questacon-The National Science and Technology Centre. https://www.questacon.edu.au/burarra-gathering/extra-information/billabong.

Boon, H. 2014. "Climate Change Ignorance: An Unacceptable Legacy." Australian Education Research 42 (4): 405-27. https://doi.org/10.1007/s13384-014-0156-x. 
Boon, H., A. Cottrell, D. King, R. B. Stevenson, and J. Millar. 2012. "Bronfenbrenner's Bioecological Theory for Modelling Community Resilience to Natural Disasters." Natural Hazards 60 (2): 381-408. https://doi.org/10.1007/s11069-011-0021-4.

Boon, H., and P. J. Pagliano. 2014. "Disaster Education in Australian Schools." Australian Journal of Disaster Education 30 (2): 187-97.

Burge, A. 2015. "Rainbow Serpent." http://www.poemhunter.com/best-poems/anthony -burge/rainbow-serpent.

Carney, R. 2015. "Musical Terms and Their Definitions.” http://www.robertcarney.net/musical -terms-definitions.htm.

Coffman, S. 1998. "Children's Reactions to Disaster." Journal of Paediatric Nursing 13 (6): 376-82.

Danielson, K. E., and S. C. Dauer. 1990. "Celebrate Poetry through Creative Drama." Reading Horizons 31 (2): 136-48.

Dinham, J. 2011. Delivering Authentic Arts Education. Melbourne: Cengage Learning Australia.

Dreamtime. n. d. "Aboriginal Art Online." Accessed August 2, 2018. http://www.aboriginalartonline.com/culture/dreaming.php.

Dufty, N. 2009. "Natural Hazards Education in Australian Schools: How Can We Make It More Effective?" The Australian Journal of Emergency Management 24 (2): 13-16. 2014. "Opportunities for Disaster Resilience Learning in the Australian Curriculum." The Australian Journal of Emergency Management 29 (1): 12-16.

Elangovan, A. R., and S. Kasi. 2014. "Psychosocial Disaster Preparedness for School Children by Teachers." International Journal of Disaster Risk Reduction 12 (June): 119-24. https://doi.org/10.1016/j.ijdrr.2014.12.007.

Ferguson, K. 2014. "Performing Poetry: Using Drama to Increase the Comprehension of Poetry." What Works? Research into Practice. http://www.edu.gov.on.ca/eng/ literacynumeracy/inspire/research/ww_performpoetry.pdf

Flensburg, A. 2010. "Poetry Power: Using Poems in Environmental Education." Green Teacher 87: 16-22.

Forster, E. 2006. "The Value of Songs and Chants for Young Learners." Encuentro 16: 63-8.

Frost, J. L. 2005. "Lessons from Disasters: Play, Work and the Creative Arts." Childhood Education 82 (1): 2-8. http://doi.org/10.1080/00094056.2005.10521332.

Fuhrmann, S., L. D. Stone, M. C. Casey, M. D. Curtis, A. L. Doyle, B. D. Earle, D. D. Jones, P. Rodriguez, and S. M. Schermerhorn. 2008. "Teaching Disaster Preparedness in Geographic Education." Journal of Geography 107 (3): 112-20. http://doi.org/10.1080/00221340802458482.

Gangi, J. M., and E. Barowsky. 2009. "Listening to Children's Voices: Literature and the Arts as Means of Responding to the Effects of War, Terrorism, and Disaster." Childhood Education 85 (6): 357-63.

Gattenhof, S. J. 2014. "Thinking as If You Are Another: Drama, Persuasive Language and Pretexts." Australian Curriculum: Aligning Learning Areas Queensland Studies Authority, March 22, 2014. Brisbane, QLD: Brisbane Convention Centre. Unpublished. http://eprints.qut.edu.au/69079.

Gauguin, Paul. "Q.d. "Quotes." Accessed July 30, 2018. http://www.azquotes.com/quotes/topics/cyclones.html.

Great Australian Inland Sea. 2018. "The Gondwana and the Eromanga Sea." Accessed August 1, 2018. http://www.nma.gov.au/kspace/teachers/prehistoric/learning/sea.

Grindlay, J., and K. M. Breeze. 2016. "Planning for Disasters Involving Children in Australia: A Practical Guide." Review Article. Journal of Paediatrics and Child Health 52: 204-12.

Guss, F. G. 2005. "Dramatic Playing beyond the Theory of Multiple Intelligences." Research in Drama Education: The Journal of Applied Theatre and Performance 10 (1): 43-54. 
Haring. U. 2012. "Exploring Content, Interpretation and Development-Making Sense of Children's Drawings." Unpublished dissertation, James Cook University.

Haring, U., and R. Sorin. 2016. "The Cyclone as Catalyst." etropic 15 (1): 89-99. https://journals.jcu.edu.au/etropic/article/view/3305/3250.

Haring, U., R. Sorin, and N. Caltabiano. 2017. "To Teach and How to Teach the Holocaust: That Is the Question." International Journal of Humanities Education 15 (1): 19-28. https://doi.org/10.18848/2327-0063/CGP/v15i01/19-28.

Hartigan, P. J. (alias J. O’Brien). 1921. “'We'll All Be Rooned,' Said Hanrahan.” http://www.catholica.com.au/brianstake/010_bt_print.php.

Hayward, P. 2010. "Numinous Ambience: Spirituality, Dreamtimes and Fantastic Aboriginality." Screen Sound. http://www.kooriweb.org/foley/resources/media/hayward.pdf.

Izadkhah, Y. O., and M. Hosseini. 2005. "Towards Resilient Communities in Developing Countries through Education of Children for Disaster Preparedness." International Journal for Emergency Management 2 (3): 138-48.

Kookaburra. n.d. "Birdlife Australia." http://birdlife.org.au/bird-profile/laughing-kookaburra.

Keeney, G. 2004. "Disaster Preparedness: What Do We Do Now?" Journal of Midwifery \& Women's Health 49 (4): 2-6.

Kousky, C. 2016. "Impacts of Natural Disasters on Children." The Future of Children 26 (1): 73 92.

Lane, R., and P. Coutts. 2012. "Students' Alternative Conceptions of Tropical Cyclone Causes and Processes." International Research in Geographical and Environmental Education 21 (3): 205-22. http://doi.org/10.1080/10382046.2012.698080.

Lane, R., and S. Catling. 2016. "Preservice Primary Teachers' Depth and Accuracy of Knowledge of Tropical Cyclones." Journal of Geography 115 (5): 198-211. http://doi.org/10.1080/00221341.2016.1153133.

Lusebrink, V. B. 2004. "Art Therapy and the Brain: An Attempt to Understand the Underlying Processes of Art Expression in Therapy." Journal of American Art Therapy Association 21 (3): $125-35$.

Mackeller, D. 1908. "My Country." http://www.poemhunter.com/poem/my-country.

Maher, L. 2014. "The Southern Cross-A Star Guide." Accessed August 1, 2018. http://www.abc.net.au/local/stories/2014/01/23/3931015.htm.

Malchiodi, K. 2009. "Resilience Matters in Traumatized Children's Lives-and Sensory Activities Make the Difference. Enhancing Resilience Is a Matter of Engaging the Senses." https://www.psychologytoday.com/blog/arts-and-health/200907/resilience -matters-in-traumatized-childrens-lives-and-sensory-activities.

Mangione, G. R., N. Capuano, F. Orciuoli, and P. Ritrovato. 2013. "Disaster Education: A Narrative Approach to Support Learning, Motivation and Students' Engagement." Journal of e-learning and Knowledge Society 9 (2): 129-52.

Mannix, I. 2012. Great Australian Floodstories. Sydney, Australia: Harper Collins.

Mothers Helping Others. 2006. Cyclone Larry: Tales of Survival from the Children of North Queensland. Australia: Mothers Helping Others, Inc.

Mueller, A. 2011. "Australia Floods: We'll Wade on as We Always Do.” The Telegraph, January 12, 2011. http://www.telegraph.co.uk/news/worldnews/australiaandthepacific/australia /8256085/Australia-Floods-Well-wade-on-as-we-always-do.html.

Moustaki, N. 2001. The Complete Idiot's Guide to Writing Poetry. Indianapolis: Alpha Books, A Pearson Education Company.

Ronan, K. R., K. Crellin, D. M. Johnston, K. Finnis, D. Paton, and J. Becker. 2008. "Promoting Child and Family Resilience to Disasters: Effects, Interventions, and Prevention Effectiveness." Children, Youth and Environments 18 (1): 332-53. 
Ronan, K. R., E. Alisic, B. Towers, V. A. Johnson, and D. M. Johnson. 2015. "Disaster Preparedness for Children and Families: A Critical Review." Current Psychiatry Reports 17 (58): 1-10. http://doi.org/10.1007/s11920-015-0589-6.

Ronan, K. R., K. Haynes, A. Amri, B. Towers, E. Alisic, N. Ireland, A. Amri, S. Davie and M. Petal. 2016. "Child-Centred Disaster Risk Reduction: Can Disaster Resilience Programs Reduce Risk and Increase the Resilience of Children and Households?" Australian Journal of Emergency Management 31 (3): 49-58.

Russel-Bowie, D. 2006. MMADD about the Arts! An Introduction to Primary Arts Education. Frenchs Forest, Australia: Pearson Education.

Shaw, J. A. 2012. "Disaster, Children and Chance Happenings." Psychiatric News 47 (11): 18.

Skrzypaszek, J. 2011. "Cross-Cultural Sharing of Spirituality." Theology Conference Papers, Paper 3. http://research.avondale.edu.au/theo_conferences/3.

Smilan, C. 2009. "Building Resilience to Childhood Trauma through Arts-based Learning." Childhood Education 85 (6): 380-84. http://doi.org/10.1080/00094056.2009.10521405.

Sorin, R. 2003. "Reconceptualising Fear in Young Children." Australian Research in Early Childhood Education 10 (1): 121-34.

State of Queensland Studies of Society and Environment (SOSE). 2000. "Sourcebook Modules." Accessed August 1, 2018. https:/www.qcaa.qld.edu.au/p-10/past-curriculumdocuments/years-1-10-syllabuses/studies-of-society-environment/sourcebook-modules

Storyboards. n.d. "What Are Storyboards?" Accessed August 2, 2018. https://www.scholastic.com/teachers/articles/teaching-content/what-are-storyboards/.

Taçon, P. 2005. "Chains of Connection." https://www.researchgate.net/profile/Paul_Tacon /publication/29458886_Chains_of_connection/links/5447319c0cf22b3c14e0c0c0.pdf.

Usher, K., P. Buettner, C. West, J. Millis, C. Woods, M. Mason, H. Boon, and S. J. Chamberlain. 2013. "Preparedness for and Impact of Tropical Cyclone Yasi in North Queensland, Australia." Prehospital and Disaster Medicine 28 (3): 273-78.

Van Aalst, M. K. 2006. "The Impacts of Climate Change on the Risk of Natural Disasters." Disasters 30 (1): 5-18.

Wooding, S., and B. Raphael. 2004. "Psychological Impact of Disaster and Terrorism on Children and Adolescents: Experiences from Australia." Prehospital and Disaster Medicine 19 (1): 10-20.

Woods, C., C. West, P. Buettner, and K. Usher. 2014. “'Out of Our Control': Living through Cyclone Yasi." International Journal of Qualitative Studies on Health and Well-being 9: $1-11$.

World Disaster Report (WDR). 2016. Resilience: Saving Lives Today, Investing for Tomorrow. Geneva: World Disaster Report. http://www.ifrc.org/Global/Documents/Secretariat /201610/WDR\%202016-FINAL_web.pdf.

\section{ABOUT THE AUTHORS}

Ute Haring: PhD Student, College of Arts, Society and Education, Division of Tropical Environments and Societies, Cairns, Queensland, Australia

Reesa Sorin: Associate Professor of Early Childhood, College of Arts, Society and Education, Division of Tropical Environments and Societies, Cairns, Queensland, Australia

Nerina J. Caltabiano: Associate Professor of Psychology, Department of Psychology, College of Healthcare Sciences, Division of Tropical Health \& Medicine, Cairns, Queensland, Australia 


\section{The International Journal of Pedagogy and}

Curriculum is one of ten thematically focused journals

in the collection of journals that support The Learner

Research Network-its journals, book series,

conference, and online community. The journal

explores the processes of designing and implementing

learning experiences and the dynamics of learning.

As well as articles of a traditional scholarly type, this journal invites presentations of practice-including documentation of curricular practices and exegeses of the effects of those practices.

The International Journal of Pedagogy and Curriculum is a peer-reviewed, scholarly journal. 